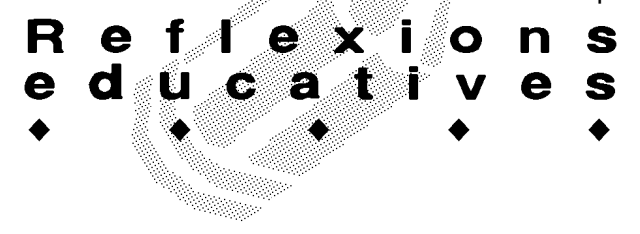

\title{
DUES CARES DELS PROJECTES JUVENILS: EL NAUFRAGI I L'EXCEL·LENT
}

\author{
Enrique Fuentes Goyanes. Àrea de Teoria i Història de l'Educació
}

\begin{abstract}
"Recordo la crisi que vaig tenir fa temps: Vaig dir que era la reina d'Espanya. En el fons, jo prou sabia que no era veritat. Era como una nena que juga amb una nina i que sap que la seva nina no és viva, tot i que se'n vol persuadir... tot em semblava encisat... jo era com una comediant que hagués interpretat un paper $i$ s'hagués ficat a la pell del seu personatge. Estava convençuda... no pas del tot. Jo vivia en un món imaginari».
\end{abstract}

En una obra de Jean-Paul Sartre recentment recuperada (Sartre, 1940) hi ha aquest bonic exemple per explicar les patologies de la imaginació d'una jove esquizofrènica. Aquest símptoma que molts autors postmoderns atribueixen a la psicologia social dels països postindustrials europeus de finals del segle $X X$, és especialment sentit pels joves que busquen una identitat pròpia, però que no poden desfer els nusos que els fan la pròpia família i l'escola secundària obligatòria, per impedir que volin i es perdin. S'ha projectat una doble imatge que produeix el desdoblament de sentiments, la fidelitat a la família, el respecte als professors i la necessitat d'evadir-se d'aquesta gàbia daurada que cada cop té més barrots en forma de "deures", per assolir els "fàcils béns" que ofereix el món i la publicitat del mercat "obert". Aquesta percepció imaginària del món exterior il-limitat que atrau en forma de somnis i il-lusions de "voler ser així" i de "voler tenir com", xoca amb les formes "realistes" de presentar les possibiitats familiars d'aconseguir-ho, i amb les barreres acadèmiques per entendre-ho i aprendre-ho, formes persuasives de dir "tu no pertanys a aquesta categoria", "conforma't amb el que tens i amb el que puguis".

Les decepcions personals, en especial l'enfonsament del suport familiar o la crisi sentimental dels pares -que eren el model de suport mutu i solidari-, fan que la pèrdua de confiança s'encasti a l'ànim convivencial dels joves. A tot això s'hi suma, en molts casos, el naufragi de les expectatives escolars, el fracàs en algunes assignatures, el bombardeig diari i reiteratiu que forma part de la repressió acadèmica i cristal-litza en la desmotivació, i les rutines perverses d'alguns professors. Encesos els ànims, es perd el coratge que animava la "lluita per sobreviure" i els pensaments nihilistes enfosqueixen la imaginació.

En el sistema uniformat i saturat de continguts, merament instrumentals, rutinaris, el baix interès es converteix en poca qualitat dels treballs, acompanyant-ho de constants humiliacions que trenquen l'autoestima dels adolescents. Els nois, i cada cop més les noies, fugen a camps alternatius, on no s'hi entra de forma disciplinària, abraçant l'apatia o enrolant-se en les més furioses rebel-lies del carrer, o pirateries als mars polisèmics del seu ordinador personal.

A altres models escolars, on generalment existeix una predisposició tripartida de pares, ensenyants i alumnes amb un definitiu instint elitista, la imaginació creativa i la intel-ligència analítica asfixien i desvien els sentiments filantròpics, amb la finalitat última d'aconseguir l'èxit, l'acumulació de poder polític i una respectable fortuna personal. Això compensarà tot l'esforç de la família, justificarà el mètode de selecció familiar i els procediments pedagògics inelàstics, i la resta de sacrificis ascètics, inclòs el del considerat primitivisme del sexe, relegat a una d'aquestes associacions de conveniència, més útil que la relació de convivència.

L'actual model de Sistema Educatiu, que porta quasi bé un segle de retard respecte a països com França, estructura un ensenyament secundari obligatori amb criteris igualitaristes per una banda i amb contradiccions culturals per l'altra: "Tots iguals i tots diferents". Propicia un procés de formació postobligatori a dues velocitats, els que superen els nivells selectius de les carreres científiques i de tècniques superiors, i els que s'acumulen a tota la resta d'expectatives.

Mentre la cultura capitalista, com indica Berger (1989), presenta infinites $\mathrm{i}$ indefinides vies per a la realització personal, les famílies amb un caire més conservador veuen amb bons ulls la jornada parcial per a les mares, amb el que suposa de tornada als rols de la llar i a l'allunyament dels llocs de responsabilitat de les dones a les institucions públiques i a les empreses. L'escola, retardada per l'amuntegament de continguts fonamentals, és obligada en molts casos a la burocratització, quan no a la distribució de ro/s, amb 


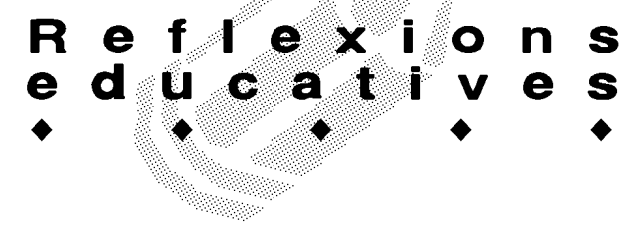

unes normes no escrites però que són latents als curricula amagats de cadascun dels seus subjectes. Ambdues situacions perseveren en l'immobilisme i resten a les noves generacions el gaudi dels mitjans plurimòrfics dels quals disposen extraescolarment.

Malgrat la necessitat d'un cert convencionalisme educatiu que valori el millor de la tradició i del progrés, l'estímul dels interessos personals i de les il-lusions juvenils ha de sobreposar-se a qualsevol forma de revisionisme històric, o del reaccionari realisme social.

Les feministes han lluitat conjuntament amb els antiracistes per un repartiment just de les responsabilitats $i$ beneficis socials i culturals per a qualsevol home 0 dona. Un segle d'ensenyament secundari ens dóna encara un pobre resultat per aquests ideals d'universalització dels drets humans. De la mateixa forma que en la societat tradicional hi havia uns marcats rols de gènere i de classe, actualment segueix el desequilibri entre carreres i professions definides majoritàriament com a masculines o femenines, a banda de la selecció de classe social: per a rics, privades; classes populars, públiques.

Guichard (1995) ha estudiat les formes de representació del futur en els joves i insisteix que l'escola fa percebre diferències específiques a l'hora d'orientar uns o altres joves, més enllà de les seves aptituds concretes. L'actual sociologia del professorat, majoritàriament femení en alguns nivells, envellit en major proporció del necessari en molts centres, arriba a prefigurar un discurs que orienta deterministament els curricula de les noves generacions, consensuat en molts casos amb les presumpcions culturals de les famílies.

El sistema escolar és taxonòmic, com insisteixen els tecnòcrates, i reclassifica els gèneres, les classes socials i els individus, segons les instàncies filosòfiques de cada època, i a les acaballes del segle $X X$ sofrim de fonamentalisme, es torna a l'educació religiosa i patriòtica i de neoconservadurisme, es menysprea la institució pública i es potencia la lliure competència dels centres privats.

No és l'organització escolar en ella mateixa, diu Guichard, la que determina que les noies tinguin millors resultats en unes matèries, o desenvolupin un tipus d'actituds genèriques, però sí que es té constància que hi ha nombroses formes de persuasió, a l'educació familiar i a la pedagogia institucional, perquè els nois perseverin en carreres de ciència i tecnologia, en els cicles llargs i costosos, i les noies demostrin millors actituds en magisteri o infermeria, en cicles curts $i$, en definitiva, en feines a temps parcial, com hem indicat amb certa ironia. El mateix es pot dir de l'orientació generosa de certes minories culturals i en molts casos peculiars de notòria discriminació, enfront de les possibilitats d'exercir treballs públics.

Amb aquests prejudicis només s'aconsegueix accentuar les contradiccions dels individus cridats a l'èxit. ¿Què passa quan els joves en els quals es dipositen tantes esperances fracassen, no aconsegueixen bons resultats, o tenen pitjors sortides laborals que les promeses? La desil-lusió es manifesta quan es fa competir un inconformista, o es dirigeix a un ambiciós egoista.

Als centres de formació professional, majoritàriament masculins, aquesta taxonomia de selecció dels excel./ents produeix un complex d'inferioritat entre els excedents.

Els alumnes dels tallers de mecànica, els que porten la granota blava, estan ensinistrats a l'estil del taylorisme industrial, en la disciplina de la sincronització i en la dependència de la direcció. Els "electrònics" són més autosuficients, tancats en ells mateixos i corrent virtualment entre els circuits virtuals dels ordinadors, s'associen esotèricament, però el dia que la fan, la fan bona, uns cops són individualistes, altres vegades simplement cínics i distants, se sap que són "especialistes", sense ells el món de la teledirecció no pot funcionar, es fan imprescindibles.

\section{Els nàufrags sempre troben un paradís}

Kokosowski (1983) a la seva obra Les Lycéens à l'enseignement supérieur, ens adverteix que la construcció d'un futur, especialment professional, es fonamenta en les avaluacions referides a models de vida actuals. Estan marcats pels estereotips difosos, per una banda, per la visió educadora dels pares i per la prospectiva professional dels pedagogs, recolzada pel prediccionisme dels psicòlegs, projectant uns i altres les seves pròpies vivències i percepcions, rebudes, en part, dels usos i costums de la generació anterior de familiars $i$ acadèmics.

A aquestes experiències i expectatives immediates, els joves hi han d'integrar unes imatges rebudes metaconscientment des de l'univers dels mitjans de comunicació trans-nacionals, on s'exposen irrealment, sense dades empíriques, els models d'èxit i de fracàs d'altres personatges, de condicions político-socials de magnitud diferent a la local que es té com a referent, la qual cosa permet fer volar coloms a la il.lusió i a la fantasia. Encara que l'enjudiciament d'aquestes situacions es dóna a la vida quotidiana, els pares i els mestres no controlen l'impacte de la cultura pop, que configura un món peculiar d'interessos exclusivament adolescents, i que fa addictes a les Spices Girls a 


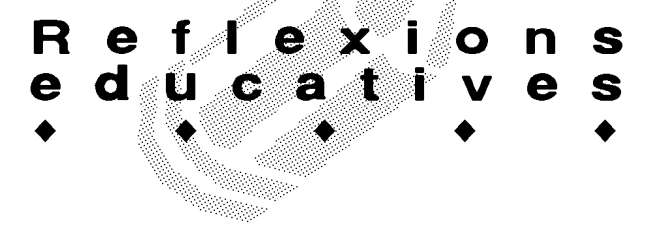

milions de seguidors de la lletra de les seves cançons, memoritzades sense esforç, molt contràriament a allò que se suposa incapacitat quan parlem de dates històriques, faltes gramaticals o fórmules de física.

Per poder fer front a la complexitat de situacions educatives, es recorre amb molta freqüència al determinisme dels pols oposats, els fracassats i els triomfadors. El grau d'eficàcia d'un sistema se centra en el conglomerat, en el núvol de punts, en el centre de gravetat de la mitjana nacional, i la mitjana nacional comparada amb altres sistemes pitjors i excel-lents. D'aquí sortiran les legitimacions de les normes curriculars normalitzadores.

Les bipolaritzacions, i la seva maniquea eficàcia, separa les opcions escolars, els bons i els dolents, els millors i els pitjors, els nois i les noies, els rics i els pobres. Des de l'estructuralisme, la bipolarització és la forma més còmoda de classificació, d'ordenació i de presa de decisions, europeus i no-europeus, catalans i no-catalans. El problema de la globalització és que introdueix el relativisme cultural, que porta inexorablement al moral i social, i estableix la legitimitat del dret a la diferència i a la dissidència.

Per facilitar la diversitat d'opcions i compromisos amb el futur professional, es presenta davant dels joves un conjunt d'alternatives, carreres curtes o llargues, estudis generals o professionalitzants, matèries fàcils que emmascaren la falta d'aptitud, assignatures difícils que requereixen dedicació i concentració, quan no una preparació específica. Això fa més assequible el criteri d'adaptació a les normes escolars i socials.

Mitjançant aquest consens de saber triar allò que convé a cadascú, la societat "oberta" tal i com la imagina Popper i l'han construïda els socialdemòcrates, forma part també de l'imaginari dels joves de secundària. El dilema llibertat / dependència queda en part resolt en el moment de l'elecció professional. Tant en els homes com en les dones, el futur va lligat a l'acceptació o no de les diferències genèriques, a banda d'altres trets de la individualitat. Després vindrà la preferència per l'ofici manual o intel-lectual, per procediments sedentaris o dinàmics, els autònoms o els dependents, els que segueixen un codi de manteniment o un treball complementari a la professió del cònjugue.

La prometeica decisió pot portar-los a posar-se ells mateixos el jou al coll, però si les circumstàncies empitjoren, el nus estreny, l'àguila del remordiment i el sentiment de fracàs faran que l'individu, abans d'ofegar-se, faci un salt mortal, fugi a una ïlla paradisíaca i es converteixi en el salvatge, que és el símbol ancestral de l'home lliure.

A mesura que la dona aconsegueix un cert poder i la mare posa un nou accent a la vida familiar, s'experimenta en els joves, mitjançant la moda i els estils de vida, una

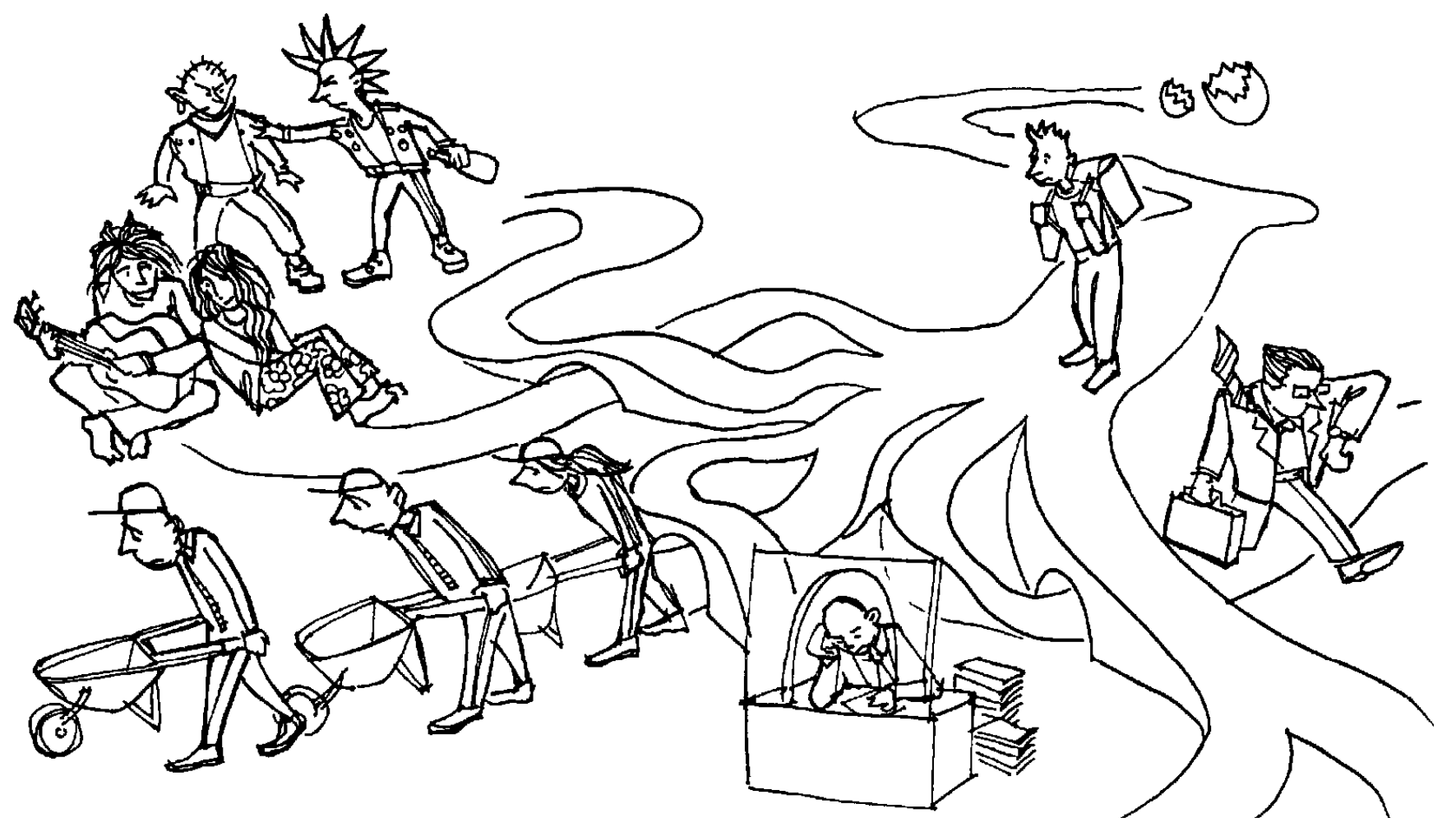




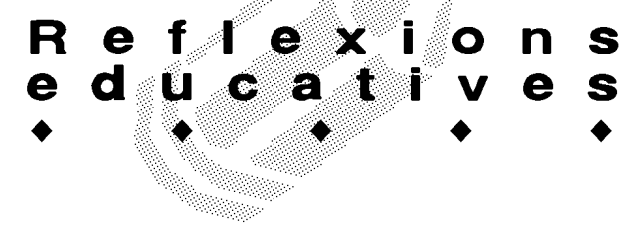

reacció neomasclista que es concreta en actituds familiars com el tallat del cabell, i fins i tot en processos psicològics profunds com el comportament fal-lòcrata i violent. Respecte a l'elecció de carrera, alguns pretenen diferenciar aquelles més masculines, contraposant Dret, com a més agressiva i competitiva, i qualsevol forma de professorat com a "més tranquil.la i assequible".

La influència de la ideologia política que es manifestà en èpoques anteriors com una forma de realització agònica dels inconformistes, en les actuacions filantròpiques dels metges, advocats laboralistes, i fins i tot dels missioners i psicòlegs, ara és menor, i l'elecció d'una carrera de fort accent social és simplement perquè es necessita una nota mitjana menor per accedir-hi, o perquè hi ha una major oferta als centres locals. En aquestes condicions, la retòrica familiar juga un paper important: mentre que es considera oportú que les filles es quedin en facultats pròximes, s'inverteix més a enviar el fill a un centre superior llunyà i més elitista, encara que en alguns casos el risc d'aquesta elecció discriminadora passa factura. La condició femenina, la manca de recursos i la decepció en el decurs dels estudis segueix essent una rèmora en la consecució del desitjat èxit professional. Només la fèrria voluntat dels que tenen il.lusió és capaç de reflotar els que quasi estan ofegats.

\section{Vida escolar i valor social}

Els subjectes socials es diferencien pel tipus d'eleccions que realitzen, fins i tot canviant la seva fisonomia, el cognom i per què no, de professió, si quan elegiren per primera vegada no ho van fer adequadament, lliurement. Per a Bordieu (1988), la família i l'escola, de forma inseparable, funcionen com els llocs en què es constitueixen, pel propi ús, les competències jutjades com a necessàries en un moment determinat del temps i com els llocs en els quals es forma "el seu preu", sancionant el que és acceptable i el que no ho és, segons criteris, en molts casos, del sentit de l'aplicació productiva. Però algunes competències específiques que requereixen el valor personal del subjecte, com l'habilitat musical, depenen de les oportunitats que ofereixen els diferents mercats per a la seva acumulació, execució i valoració. Actualment existeix un consens tancat respecte a certes habilitats ligüístiques i tècniques, idiomes i ordinadors, però ¿durant quant temps aquestes competències se seguiran valorant com a indispensables?, podrien ser una il.lusió d'un temps i d'un Iloc, il-lusió col-lectiva que no ha tingut en compte el "mercat de futurs", el seu valor es pot inflaccionar, o es pot convertir en valors permanents.
Bordieu indica la relació entre els quarters de la noblesa i el capital escolar i cultural. Si alguna cosa ha valgut la pena a les democràcies socials europees és la transició que l'educació permet per a superar el conflicte entre les classes socials: tots desitgen un futur millor per als seus fills, però algunes opcions són fraudulentes. Quantes vegades l'entestament contra la decisió de ser artista ha trencat l'Auca del Senyor Esteve, però l'èxit d'un cantant famós omple d'orgull tota la comunitat, essent facultats específiques del subjecte i, en molts casos, aconseguides i valorades prèviament en altres països.

El valor dels diplomes va indubtablement associat al valor de l'individu, i el refús d'algunes carreres d'èxit per als joves de secundària té la seva causa en el reconeixement de les pròpies limitacions i l'elecció d'altres motivacions que els donaran un altre tipus d'èxit 0 satisfacció no compartida. Però l'elecció de carrera requereix un pacte familiar on s'associa el valor de la inversió amb les capacitats de realització del subjecte, si no es té en compte un prejudici de gènere o de menyspreu professional.

Les actuals normes curriculars valoren considerablement les actituds, però a la pràctica estan sotmeses a la dictadura dels continguts, que marquen el poder de l'estament docent. Si es vol convèncer que mitjançant l'aprehensió d'aquest coneixements es tindrà accés a qualsevol professió, es limita als estudiants a un model unidimensional, com diu Marcuse, que requereix una distribució igualitària dels béns socials.

En oposició a aquesta fal-làcia d'igualtat d'oportunitats hi ha l'heterodox món de la cultura juvenil; ells saben el que vol dir "munta-t'ho com puguis". Els que no volen aprendre d'acord amb els ritmes del model escolar i es troben desmotivats per les oportunitats professionals del sistema, intueixen el bé que poden estar "desenganxats", es "pengen" del penja-robes que els proporciona "un vestit a mida", generalment amb poca roba i deixant veure la carn... s'assemblen molt a aquelles noies picants...

\section{Referències bibliogràfiques}

SARTRE, J. P. L'Imaginaire. Psychologie phénoménologique de l'imagination. Editorial Gallimard. Universitat de Lleida. Editorial El Fil d'Ariadna. 1940. Pàg. 228.

BERGER. La revolución capitalista. Editorial Península. Barcelona. 1991.

GUICHARD. La escuela y las representaciones de futuro de los adolescentes. Editorial Laertes. Barcelona. 1955.

BOURDIEU, P. La Distinción.Criterios y bases sociales del gusto. Editorial Taurus. Madrid. 1988. 